\title{
Minireview
}

\section{Recruitment of ethnic minorities into cancer clinical trials: experience from the front lines}

\author{
RP Symonds*,1, K Lord ${ }^{2}$, AJ Mitchell ${ }^{1,3}$ and D Raghavan ${ }^{4,5}$ \\ 'Department of Cancer Studies \& Molecular Medicine, University of Leicester, Osborne Building, Leicester Royal Infirmary, Leicester LEI 5WW, UK' \\ ${ }^{2}$ University Hospitals of Leicester NHS Trust, Leicester Royal Infirmary, Leicester LEI 5WW, UK; ${ }^{3}$ Leicestershire Partnership Trust, Leicester LE5 0TD, UK: \\ ${ }^{4}$ University of North Carolina School of Medicine, PO Box 32861, Charlotte, NC 28232-2861, USA; ${ }^{5}$ Levine Cancer Institute, Carolinas Healthcare \\ System, Charlotte, NC 28232-286I, USA
}

Throughout the world there are problems recruiting ethnic minority patients into cancer clinical trials. A major barrier to trial entry may be distrust of research and the medical system. This may be compounded by the regulatory framework governing research with an emphasis on written consent, closed questions and consent documentation, as well as fiscal issues. The Leicester UK experience is that trial accrual is better if British South Asian patients are approached by a senior doctor rather than someone of perceived lesser hierarchical status and a greater partnership between the hospital and General Practitioner may increase trial participation of this particular ethnic minority. In Los Angeles, USA, trial recruitment was improved by a greater utilisation of Hispanic staff and a Spanish language-based education programme. Involvement of community leaders is essential. While adhering to national, legal and ethnical standards, information sheets and consent, it helps if forms can be tailored towards the local ethnic minority population. Written translations are often of limited value in the recruitment of patients with no or limited knowledge of English. In some cultural settings, tape-recorded verbal consent (following approval presentations) may be an acceptable substitute for written consent, and appropriate legislative changes should be considered to facilitate this option. Approaches should be tailored to specific minority populations, taking consideration of their unique characteristics and with input from their community leadership.

British Journal of Cancer (2012) I07, 1017-1021. doi:I0.1038/bjc.2012.240 www.bjcancer.com

Published online 31 May 2012

(C) 2012 Cancer Research UK

Keywords: clinical trials; ethnic minorities; cancer clinical trials

A very important international problem is the existence of significant disparities in cancer care, with uneven distribution of resources, incidence figures, access to care and treatment outcomes. This is most marked in such groups as ethnic and racial minorities, those with mental ill health, the elderly, those without some form of health insurance, and geographically isolated populations (Goodwin et al, 2004; Raghavan, 2007; Goss et al, 2009; President's Cancer Panel, 2011). Several factors contribute to this (Table 1; Raghavan, 2007). Of importance, nationalised medical systems, which provide some form of health insurance for whole populations, constitute no panacea, and significant disparities continue to exist in cancer care in Australia, New Zealand (Garvey et al, 2011) and elsewhere. As a result, these under-served populations can expect higher incidence rates, worse access to prevention and screening, later diagnosis or treatment and reduced involvement in clinical cancer trials (Raghavan, 2007; Goss et al, 2009; President's Cancer Panel, 2011) and ultimately inferior survival.

Clinical trials have considerably improved the treatment of cancer, and it has been shown that participants in clinical cancer trials have better outcomes than are reported in the population at large (Djulbegovic et al, 2008). However, we must acknowledge

*Correspondence: Dr RP Symonds; E-mail: rps8@le.ac.uk Received 28 November 201 I; revised 20 April 2012; accepted 3 May 2012; published online 31 May 2012 that enrolment in a clinical trial, especially a phase I study, may not benefit individual patients. Although most participants enrolled in trials remain highly satisfied with their decision to participate (Jefford et al, 2011), not all patients view participation as favourable; for example, in one study, $55 \%$ felt trial participation could be upsetting and $25 \%$ thought the outcome of their treatment might be adversely affected (Corbett et al, 1996). It should be acknowledged that motivation to enrol in trials is complex and may include altruism, desire for improvement of one's own health, out of a sense of obligation to the doctor and the expectation of increasing scientific knowledge (Hussain-Gambles et al, 2004).

Many barriers to participation exist, especially in minority populations (Mills et al, 2006; Ford et al, 2008; Wells and Zebrack, 2008; Shah et al, 2010). Examples include concerns about efficacy and safety of trials, fear of additional financial costs, concern about randomisation, trial burden, loss of confidentiality, dependency issues and cultural barriers. It has recently been estimated that $<5 \%$ of US cancer patients are enrolled into trials and ethnic minorities plus individuals of low socio-economic status are less likely to be trial participants (Ford et al, 2008). What is uncertain is how many patients are explicitly offered participation. The very low uptake of trials is widely accepted as an unsatisfactory situation that has recently been recognised by the American Society of Clinical Oncology, which has embarked on an intensive campaign to increase participation of racially and ethnically diverse populations into cancer clinical trials and to improve 
Table I Impediments to optimal cancer care for minority populations

\begin{tabular}{|c|c|c|}
\hline Parameter & Impediment & Potential solutions \\
\hline \multirow[t]{2}{*}{ Fiscal } & Insurance: medical, drugs & $\begin{array}{l}\text { Create indigent safety net(s); regulation of pharmaceutical industry; evidence-based use of cancer therapies; limi } \\
\text { provider incentives that may promote disparities of care; education regarding diet, smoking, and so on. among } \\
\text { indigent; strategies to deal with diet and carcinogen exposure among indigent }\end{array}$ \\
\hline & $\begin{array}{l}\text { Poverty; lack of family support } \\
\text { (especially the working poor) }\end{array}$ & $\begin{array}{l}\text { Health insurance; minimum wage; create indigent safety net(s); improved social support systems; improved } \\
\text { patients transport systems for indigent }\end{array}$ \\
\hline \multirow[t]{2}{*}{ Cultural } & $\begin{array}{l}\text { Cancer stigma; fear; poor expectations } \\
\text { of outcome of cancer treatment }\end{array}$ & Education within community; education of politicians and legislators regarding the problem \\
\hline & $\begin{array}{l}\text { Suspicion regarding clinical trials } \\
\text { and experimentation }\end{array}$ & Education within community; use of community role models; engagement of community physicians \\
\hline \multirow[t]{2}{*}{ Access } & Lack of medical 'home' & $\begin{array}{l}\text { Accessible cancer care centres; patient navigator systems; education regarding availability and use of medical } \\
\text { facilities; outreach facilities within the community }\end{array}$ \\
\hline & $\begin{array}{l}\text { Alienation of minority patients from } \\
\text { the majority medical community }\end{array}$ & $\begin{array}{l}\text { Involve community leaders; train more minority oncologists; increase minority support staff; cultural competenc) } \\
\text { training of majority physicians }\end{array}$ \\
\hline $\begin{array}{l}\text { Knowledge } \\
\text { base }\end{array}$ & $\begin{array}{l}\text { Insufficient knowledge of the specifics } \\
\text { of cancer in minority populations }\end{array}$ & $\begin{array}{l}\text { Increase diversity and disparity research and funding; education of majority physicians and scientists; expand } \\
\text { access to minority-specific clinical trials; expand minority pharmacology research; create local and national } \\
\text { databases to monitor progress in disparities of care }\end{array}$ \\
\hline
\end{tabular}

Reproduced with permission from Raghavan (2007).

access to cancer care for these populations (Goss et al, 2009). In May 2010, a symposium on accrual to clinical trials was held as a collaboration between the US National Cancer Institute and the American Society of Clinical Oncology. This meeting included a full session on methods to improve accrual of minorities and under-served populations onto cancer clinical trials. However, there is also a danger of over-participation when patients felt pressured to enrol (see below).

Trial participation may vary by setting and by country. In the United Kingdom, the National Cancer Research Network (NCRN) was established in 2001 and this may have helped increase patient recruitment into cancer trials from $<3.5 \%$ of patients being entered into clinical trials to $12 \%$ (Stead et al, 2011). The NCRN has not commented about the ethnic mix of patients within these studies, although a case study from the University College London Hospital Trust found that recruitment levels into clinical trials were $30 \%$ lower for minority ethnic patients compared with white cancer patients after adjusting for disease, age and gender (Godden et al, 2010). The failure to enter certain population groups into clinical trials is inequitable with respect to outcomes (Djulbegovic et al, 2008), but is also important in that absence of specific population subsets could have implications regarding the safety and efficacy of the trial regimen, especially if it includes new drugs (Hussain-Gambles et al, 2006).

In this review, we will examine the published international experience and our own local experience and we will make recommendations that may enhance ethnic minority recruitment into clinical trials. A preliminary search was carried out via Medline, Pubmed, CINAHL, psycINFO, psycARTICLE, social science citation and science citation indexes. The following terms were used: patient selection, communication barriers, language, culture, attitudes, research, trials, ethnic minorities, individual ethnic groups (e.g., Asian, South Asian, Indian) and countries including UK, India and Canada. Relevant papers were also found by searches for known researchers in the field and by following up references from papers that described recruitment experiences among ethnic minorities. This was done in a more iterative manner. Finally, US and UK government websites were searched for details of policies relevant to the subject. We also present our personal experience including programmes that we have observed, as good practice points, given the paucity of definitive, published data and guidelines.

\section{HUMAN AND TRIAL DESIGN FACTORS NEGATIVELY INFLUENCING THE RECRUITMENT OF ETHNIC MINORITY PATIENTS}

The relationship between patients and their doctors is crucial to the success of recruitment into clinical research. The most frequently quoted barrier to minority accrual to cancer-related trials is mistrust of research and the medical system (Ross et al, 1999; Hussain-Gambles et al, 2004; Ford et al, 2008). In a recent meta-analysis of seven qualitative studies among Indians resident in Singapore, US and India, mistrust of researchers was regarded as a significant barrier by $26 \%$ of participants (Shah et al, 2010). Practices in the Indian subcontinent have coloured the views of Indian and Pakistani patients in the United Kingdom. The perceived poor reputation of research methods in parts of the Indian subcontinent, where consent might not be sought or where the vulnerable populations may be exploited, may have led to non-participation of British South Asians in UK studies (Hussain-Gambles et al, 2006). Mistrust may become a more prominent issue given the increase in outsourcing of multinational clinical trials to countries within the Indian subcontinent.

In the United States, studies based on survey questionnaires and focus groups have suggested that various historical factors, such as the infamous Tuskegee syphilis observation study, have undermined trust in medical research among minority groups (Bates and Harris, 2004).

Modern design and practice in clinical trials may also foster poor accrual. For example, in the western world, there is a normal statutory requirement for consent to be given by the individual concerned, and the individual within the trial is the focus of the information delivery and consent process. In contrast, most countries in South and East Asia have a collectivist culture and it may be the norm for the wellbeing of the group or family to supersede the needs of the individual members. Within British South Asian communities, the decision to take part in a clinical trial may be a collective decision taken by the family rather than the individual. The decision may be influenced by socio-economic factors, as ethnic minorities in many western societies have a lower average family income than the majority population. Loss of income or costs incurred in participation of research may be factors that inhibit participation as research often requires more visits to hospital. In addition, ethnic perceptions of cancer, death, benefits of treatment and the associated stigma of this disease can 
have dramatic impacts on choices regarding treatment and participation in trials (Lord et al, 2011a).

This is compounded by rigorous exclusion criteria, which are purportedly written to improve safety. For example, African Americans have higher incidences of significant co-morbid conditions, such as diabetes mellitus, hypertension and ischaemic heart disease, than do the majority population (President's Cancer Panel, 2011). However, many clinical trials require excellent performance status and absence of significant intercurrent medical disorders, thus excluding many minority patients from participation.

Research Ethics Committees require all information to be translated into the language of the likely participants. The provision of information relies on literacy skills of the participant and their family. Problems with this approach have been seen within the University Hospitals of Leicester, particularly with Gujarati-speaking patients who invariably cannot read the Gujarati translations as this is largely a spoken language. Many have English-reading skills but in some this may be inadequate to understand research concepts such as randomisation and the need for written consent. The use of a translator may help but technical words may have no direct translation into Indian languages risking misunderstanding. For instance, there is no word for cancer in Hindi and Gujarati and no acceptable term for breast cancer. This may explain, in part, why $20 \%$ of women of South Asian origin in the city of Bradford in one study had not heard of breast cancer (Bahl, 1996).

International studies have shown that the regulatory setting of many clinical trials is a deterrent to participation, with the emphasis on written consent, closed questions and form filling (Sood et al, 2009). Elements of the research process have been found to be disrespectful by some, for example, where the mother tongue is predominantly a spoken language being required to sign a consent form may imply a lack of trust in one's word (Sheikh, 2006). A request for a signature on a form that may be perceived as a written contract may cause offence. Within some South Asian populations, the cancer diagnosis is a stigma that may attach itself to the family as well as the individuals concerned, and cancer can be seen as a social blight on the family and its future prospects (Lord et al, 2011a). Cancer is not the only illness associated with stigmatisation in British South Asians. Rooney et al (2011) found fear of stigmatisation was a barrier to asthma research participation among British South Asians in London and Edinburgh.

Lack of medical insurance may be a barrier to cancer trial entry in the United States. In the ASCO Policy Statement, it was noted that more than 1:3 Latinos and American Indians/Alaska natives do not have health insurance. Among African Americans and Asians 1:5 is uninsured (Goss et al, 2009). Paradoxically, even if the patient is insured, the insurance company may not allow clinical trial participation. A study from Johns Hopkins Hospital revealed $13.6 \%$ of patients who had signed informed consent documents to enrol in cancer treatment trials were denied entry into these trials by their insurers (Klamerus et al, 2010).

\section{INSIGHTS FROM LEICESTER STUDIES}

The county of Leicestershire (population 644700) has a predominantly white population (white $89.2 \%$, non-white ethnic minorities (mainly from the Indian subcontinent $10.7 \%$ )) and is served by a single cancer centre at the Leicester Royal Infirmary. The city of Leicester (population 292600) has a much larger non-white population (in 2007, 42.4\%). At the Leicester Royal Infirmary, a series of questionnaire studies was performed, examining the information needs and coping mechanisms of British white and British South Asian cancer patients of predominantly Gujarati origin. In the initial pilot studies patients were invited to take part by a senior male doctor who was part of the treatment team. Recruitment was better in these studies as there was a symbiotic relationship based on patient/physician trust. In contrast, in the latest study, attempts to recruit patients by persons of perceived lesser hierarchical status (senior nurses and radiographers) were less successful. Factors such as stress, denial, avoidant behaviour, socio-economic reasons, consent reversed by family decision and travel to countries of origin were identified as reasons for poor recruitment/retention of study patients. The information given to the patient at the request of the Ethics Committee was heavily based on consent and information sheets required for randomised control trials. In particular, a section entitled 'what if something goes wrong' caused many to be confused and wary.

The Leicester Royal Infirmary experience is that ethnic minority patients have a considerable amount of trust in their General Practitioners (GPs). Within a pilot study, 66\% of British South Asian cancer patients said their preferred source of information (including the cancer diagnosis) was the GP rather than a hospital specialist. By contrast, $82.9 \%$ of British white patients wanted to be given the cancer diagnosis and other information by a hospital specialist (Muthu Kumar et al, 2004). In a later study, $49.5 \%$ of British South Asians vs $16.9 \%$ of British white patients indicated they would prefer to hear sensitive information from their GP rather than hospital doctors (Lord et al, 2011b). Although it remains to be tested, we feel a greater partnership role between the hospital and GPs may increase trial recruitment.

\section{INSIGHTS FROM LOS ANGELES}

Towards the end of the 1990s, at the USC Norris Comprehensive Cancer Center, Los Angeles, clinical cancer trial accrual for the Hispanic population was only about $10 \%$, compared with the Hispanic population demographic of $30 \%$. Consequent upon the provision of a more representative staff of Hispanic data managers and research nurses, improved translation of consent documents into Spanish, an educational campaign, and the provision of infrastructure resources to allow participation at the Los Angeles County Hospital Oncology Clinic (a component of the USC Norris Comprehensive Cancer Center), accrual of Hispanics into trials exceeded $30 \%$.

\section{CONCLUSION: THE WAY FORWARD}

The recruitment of minority patients into cancer clinical trials requires a broadly based strategy that is focused on overcoming all of the parameters that contribute to disparities of cancer care (Raghavan, 2007; President's Cancer Panel, 2011), as well as specific issues relating to the design and conduct of cancer trials. A review of factors that may influence participation found relatively little direct evidence about what works (Yancey et al, 2006). Following a review of the literature and three qualitative interview studies of health professionals including interviews of 60 South Asian lay people and 15 South Asian trial participants HussainGambles et al (2006) made the suggestions listed in Table 2 to improve recruitment of British South Asian patients into trials.

Table 2 Methods to improve clinical trial recruitment of British South Asian patients as suggested by Hussain-Gambles et al (2006)

\footnotetext{
Define the demographic and social profiles to be included

Use focus groups to identify any potential barriers

Consult representative community members to provide assistance in the study

Ensure eligibility criteria are set as wide as possible

Develop educational and recruitment approaches to attract ethnic minority health professionals

Ensuring health professionals are adequately trained in culturally and ethnically orientated service provision

Determining the most effective mass media to use in study promotion and recruitment
} 
Thus, a series of proactive steps may improve overall cancer care, in parallel with accrual to cancer trials. Some issues are simply generic and relate to the overall problem of extant disparities of cancer care internationally. Cancer trial accrual would certainly be improved if medical systems are able to address poverty, lack of education, impaired access, absence of medical 'homes' for under-served populations, refusal by health payers to support clinical trials, language barriers, suspicion of the medical establishment, and mismatching of the lay and physician populations. It is also important to focus on issues specific to clinical cancer trials. However, what works in one centre may not work as well elsewhere or may be totally inappropriate. For instance, a strategy that is successful in people largely of Gujarati origin in Leicester may not be successful in other South Asian groups elsewhere in the United Kingdom or elsewhere in the world.

To build trust in the research process, new patients require proactive education regarding the benefits of clinical research at the point of entry to the cancer centre. Posters or other communication tools in the clinical setting should emphasise the benefits of participation in the research such as the observation that patients in cancer trials usually have better outcomes than patients receiving standard therapy. Publicity material should emphasise the role of the Ethics Committee in safeguarding patients, thus explaining the reasons for the extensive series of consent documents. An example are the slide shows with a 'sisterhood' theme developed with focus group help by Sadler et al (2010) in Southern California. English and Spanish versions are available of a PowerPoint presentation to inform Hispanic and African-American women of the benefits of clinical trials. The engagement of community leaders drawn from minority and under-served populations is crucial to the success of cancer trials involving these groups. These connections should be established and tested long before the implementation of the respective studies, so that community leaders can be involved in aspects of the design and implementation of the trials.

Recruitment should occur as part of the therapeutic alliance between doctor and patient. From the Leicester Royal Infirmary experience, this should ideally be carried out by a senior physician for the reasons noted above. In a study among Bangladeshis in South Wales (Choudhary et al, 2008) it was reported that many participants in clinical trials entered 'as a favour to the researcher'. Thus, particular care should be taken to avoid coercion and to ensure that the basis for the patient's entry into the trial is sound and ethically robust. There is also a danger that oncologists can give recommendations favouring entering the trial rather than presenting a balanced view of the benefits and drawbacks of doing so (Eggly et al, 2008; Brown et al, 2011).

In Leicester, ethnic minority patients tend to choose GPs of a similar ethnic origin. Although they often have fluent command of the English language, the consultation between patient and GP is often conducted in their mother tongue. In countries with strong primary care, such as the United Kingdom, the role of the GP to facilitate entry into clinical trials should be explored further. The importance of a personal invitation from a trusted figure has not been recognised until recently. After studying the barriers that reduced participation of ethnic minorities in asthma research Rooney et al (2011) found the most effective method of recruitment was a personal invitation from a trusted GP, hospital consultant or community/faith leader. Again, caution must be exercised to avoid coercion and inappropriate use of a privileged relationship to encourage trial participation. In this setting, the practitioner must focus on maintaining the primacy of the role of patient advocate. Other strategies such as posters, leaflets and newspaper adverts were described as 'distant' and less likely to be successful.

There may be a role for patient advocates or patient navigators to explain clinical trials to patients and facilitate entry into clinical trials, as part of a broader role that relates to improving access and process in overall cancer care. However, caution should be exercised to avoid compromising the other roles, and to avoid introducing a tension between the roles of patient advocacy and support for participation in clinical trials. Simple prompts and checklists can help trialists appropriately explain key aspects that will influence participation (Brown et al, 2011). More thought and effort need to be taken in the design of information sheets and consent forms. Although these must adhere to national legal and ethical standards, it may be that more appropriate framing can be developed for minority research subjects, perhaps in consultation with minority community leaders. These documents should also include clearer explanation of the benefits of the research in addition to the enumeration of the hazards.

Invariably, Ethical Review Committees require translation of all the trial literature into the predominant languages spoken by the relevant minority communities. Our experience is that these translated documents may be of limited value. For example, in Leicester many Gujarati speakers cannot read the written versions and some Hindi translations are incomprehensible as they use classical rather than colloquial Hindi. Although challenging to Ethical Review Committees, there may need to be a greater reliance on the spoken word in the case of some ethnic minorities (for example, the use of approved, recorded presentations and consent processes), and the role of the family in decision making may need to more fully acknowledged. Tape or video recording of interviews may be an acceptable substitution for a written consent form.

Careful attention will need to be focused on the case selection biases that tend structurally to exclude patients from clinical cancer trials by setting physical and performance parameters that are too high; cancer trials that focus only on 'perfect' patients effectively serve the community quite poorly. The purpose of this review is to focus attention onto the problem, and to consider some of the unexpected confounding variables, describing some of the extant strategies that have begun to achieve progress in the field, in order to stimulate others to target this important problem.

At a time when there is slow and steady progress internationally in recruiting patients to clinical trials, involvement of many ethnic minority and under-served communities lags substantially behind. Consequently, this constituency is systematically being denied the benefits of research and progress, an iniquitous situation that must be resolved through proactive intervention of the medical practice and research communities.

\section{REFERENCES}

Bahl V (1996) Cancer and ethnic minorities-the Department of Health's perspective. Br J Cancer 74(Suppl XX1X): S2-S10

Bates BR, Harris TM (2004) The Tuskegee study of untreated syphilis and public perception of biomedical research: a focus group study. J Natl Med Assoc 96: 1051-1064

Brown R, Bylund CL, Siminoff LA, Slovin SF (2011) Seeking informed consent to phase I cancer clinical trials: identifying oncologists' communication strategies. Psychooncology 20: 361-368

Brown RF, Shuk E, Butow P, Edgerson S, Tattersall MH, Ostroff JS (2011) Identifying patient information needs about cancer clinical trials using a Question Prompt List. Patient Edu Couns 84: 69-77
Choudhury S, Brophy S, Fareedi MA, Zaman B, Ahmed P, Williams DR (2008) Intervention, recruitment and evaluation challenges in the Bangladeshi community: experiences from a peer lead educational course. BMC Med Res Methodol 8: 64

Corbett F, Oldham J, Lilford R (1996) Offering patients entry in clinical trials: preliminary study of the views of prospective participants. J Med Ethics 22: 227-231

Djulbegovic B, Kumar A, Soares HP, Hozo I, Bepler G, Clarke M, Bennett CL (2008) Treatment success in cancer. New cancer treatment successes identified in phase 3 randomised controlled trials conducted by the National Cancer Institute-Sponsored 
Co-operative Oncology Groups 1955 to 2006. Arch Intern Med 168: 632-642

Eggly S, Albrecht TL, Harper FWK, Foster T, Franks MM, Ruckdeschel JC (2008) Oncologists' recommendations of clinical trial participation to patients. Patient Edu Couns 70: 143-148

Ford JG, Howerton MW, Lai GY, Tiffany LG, Bolen S, Gibbons MC, Tilburt J, Baffi C, Tanpitukpongse TP, Wilson RF, Powe NR, Bass EB (2008) Barriers to recruiting underrepresented populations to cancer clinical trials: a systematic review. Cancer 112: 228-242

Garvey G, Cunningham J, Valery PC, Condon J, Roder D, Bailie R, Martin J, Olver I (2011) Reducing the burden of cancer for Aboriginal and Torres Strait Islander Australians: time for a co-ordinated collaborative, priority-driven, indigenous-led research program. MJA 194: 530-531

Godden S, Ambler G, Pollock AM (2010) Recruitment of minority ethnic groups into clinical cancer research trials to assess adherence to the principles of the Department of Health research governance framework: national sources of data and general issues arising from a study in one hospital trust in England. J Med Ethics 36: 358-362

Goodwin JS, Zhang DD, Ostir GV (2004) Effect of depression on diagnosis, treatment and survival of older women with breast cancer. J Am Geriatr Soc 52: 106-111

Goss E, Lopez A, Brown CL, Wollins DS, Brawley OW, Raghavan D (2009) American Society of Clinical Oncology policy statement: disparities in cancer care. J Clin Oncol 27: 2881-2885

Hussain-Gambles M, Leese B, Atkin K, Brown J, Mason S, Tovey P (2004) Involving South Asian patients in clinical trials. Health Technol Assess 8(42): 1-109

Hussain-Gambles M, Atkin K, Leese B (2006) South Asian participation in clinical trials: the views of lay people and health professionals. Health Pol 77: $149-165$

Jefford M, Mileshkin L, Matthews J, Raunow H, O'Kane C, Cavicchiolo T, Brasier H, Anderson M, Reynolds J (2011) Satisfaction with the decision to participate in cancer clinical trials is high, but understanding is a problem. Support Care Cancer 19: 371-379

Klamerus JF, Bruinooge SS, Ye X, Klamerus ML, Damron D, Lansey D, Lowery JC, Diaz LA, Ford JG, Kanarek N, Rudin CM (2010) Clin Cancer Res 16: 5997-6003

Lord K, Mitchell AJ, Ibrahim K, Kumar S, Rudd N, Symonds P (2011a) The beliefs and knowledge of patients newly diagnosed with cancer in a UK ethnically diverse population. Clin Oncol 24(1): 4-12

Lord K, Ibrahim K, Kumar S, Rudd N, Mitchell AJ, Symonds P (2011b) Measuring trust in health care professionals-a study of ethnically diverse UK cancer patients. Clin Oncol 24(1): 13-21

Mills EJ, Seely D, Rachlis B (2006) Barriers to participation in clinical trials of cancer: a meta-analysis and systematic review of patients-reported factors. Lancet Oncol 7: 141-148
Muthu Kumar D, Symonds RP, Sundar S, Ibrahim K, Savelyich BS, Miller E (2004) Information needs of Asian and White British cancer patients and their families in Leicestershire: across-sectional survey. B J Cancer 90: 1474-1478

President's Cancer Panel (2011) America's Demographic and Cultural Transformation: Implications for Cancer. US Department of Health \& Human Services: Washington, DC, pp 1-100

Raghavan D (2007) Disparities in cancer care: challenges and solutions. Oncology 21: 493-496

Rooney LK, Bhopal R, Halani L, Levy ML, Partridge MR, Gopal N, Car J, Griffiths C, Atkinson J, Lindsay G, Sheikh A (2011) Promoting recruitment of minority ethnic groups into research: qualitative study exploring the views of South Asian people with asthma. J Public Health 33(4): 604-615

Ross S, Grant A, Counsell C, Gillespie W, Russell I, Prescott R (1999) Barriers to participation in randomised controlled trials: a systematic review. J Clin Epidemiol 52: 1143-1156

Sadler GR, Gonzales J, Manpreet M, Cullen L, Lattousse S, Malcarne V, Conde V, Riley N (2010) Adapting a program to inform African American and Hispanic American women about cancer clinical trials. J Canc Educ 25: 142-145

Shah JY, Phadtare A, Rajgor D, Vaghasia M, Pradhan S, Zelko H, Pietrobon R (2010) What leads Indians to participate in clinical trials? A metaanalysis of qualitative studies. PloS One 5(5): e10730

Sheikh A (2006) Why are ethnic minorities under-represented in US research studies? PLoS Med 3(2): e49

Sood A, Prasad K, Chhatwani L, Shinozaki E, Cha SS, Loehrer LL, WahnerRoedler DL (2009) Patients' attitudes and preferences about participation and recruitment strategies in clinical trials. Mayo Clinic Proc 84: 243-247

Stead M, Cameron D, Lester N, Parmar M, Haward R, Kaplan R, Maughan T, Wilson R, Campbell H, Hamilton R, Stewart D, O'Toole L, Kerr D, Potts V, Moser R, Darbyshire J, Selby P on behalf of the clinicians' research support staff and patients involved in the National Cancer Research Networks across the UK (2011) Strengthening clinical cancer research in the United Kingdom. Br J Cancer 104: 1529-1534

Wells AA, Zebrack B (2008) Psychosocial barriers contributing to the under-representation of racial-ethnic minorities in cancer clinical trials. Soc Work Health Care 46: 1-14

Yancey AK, Ortega AN, Kumanyika SK (2006) Effective recruitment and retention of minority research participants. Annu Rev Public Health 27: $1-28$

(c) (1) (2) This work is licensed under the Creative Commons

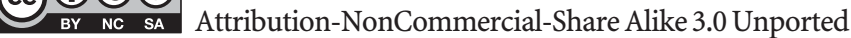
License. To view a copy of this license, visit http://creativecommons. org/licenses/by-nc-sa/3.0/ 